\title{
ANTIMICROBIAL EVALUATION OF SODIUM HYPOCHLORITE AND OZONATED WATER ON E. FAECALIS BIOFILM
}

N.Z. Ibrahim, M. Abdullah. Antimicrobial evaluation of sodium hypochlorite and ozonated water on $\mathrm{E}$. faecalis biofilm. Annal Dent Univ Malaya 2008; 15(1): 20-26.

\begin{abstract}
This study aim to evaluate antimicrobial efficacy of sodium hypochlorite $(\mathrm{NaOCl})$ and ozonated water against Enterococci faecalis biofilm. The bacterial biofilm was exposed to $2.62 \%, 1.31 \% \mathrm{NaOCl}$ and $0.1 \mathrm{ppm}$ ozonated water over a range of time periods. The presence of viable cells was determined by enumeration of colony forming units (CFU). All experiments were repeated four times $(n=4)$. The effectiveness of the agents was compared using nonparametric Kruskal-Wallis test. The result revealed that $2.62 \%$ of $\mathrm{NaOCl}$ can completely kill $E$. faecalis biofilm in 15 minutes whereas $1.31 \% \mathrm{NaOCl}$ required a longer time to produce such effect. $0.1 \mathrm{ppm}$ ozonated, however, did not exhibit any antimicrobial effect within the period of time tested. From this study, it can be concluded that $0.1 \mathrm{ppm}$ ozonated water was not comparable with $2.62 \%$ and $1.31 \% \mathrm{NaOCl}$ in antimicrobial efficacy against $E$. faecalis biofilm.
\end{abstract}

Key words: sodium hypochlorite, ozonated water, biofilm, antimicrobial efficacy

\section{INTRODUCTION}

Pulp and periradicular diseases are of microbial origin (1). E. faecalis is commonly isolated in root canals of failing treatment $(2,3)$. It is among the few facultative bacteria associated with persistent apical periodontitis (2). This bacteria species has the ability to invade dentinal tubules (4) and one of the hardest microorganisms to be eliminated once it has established itself in root canals (3). In addition, it exhibits a high level of resistance to a wide range of antimicrobial agents (5).

Bacteria in planktonic suspension and biofilm form have shown different response to antimicrobial agent tested on them. Of particular concern is that our ability to eradicate biofilm from infected hosts is substantially lower than that for dispensed, planktonic bacteria (6). A clinically valid and simple assay for microbial susceptibility testing could be based on a biofilm model. Generation of such biofilm in root canals of extracted teeth provides a more realistic scenario $(7,8)$. However, the result may be confounded by the variation in root canal
Original Article

N.Z. Ibrahim ${ }^{1}$, M. Abdullah ${ }^{2}$

1 Postgraduate Student

Department of Conservative Dentistry,

Faculty of Dentistry, University of Malaya

${ }^{2}$ Department of Conservative Dentistry,

Faculty of Dentistry, University of Malaya,

50603 Kuala Lumpur, Malaysia

Tel: $+60-3-79674883$

Fax: $+60-3-79674533$

Email: mariamabd(a)um.edu.my

Corresponding author: Dr. Mariam Abdullah

anatomy between teeth. In addition, the collection and preparation of the teeth prior to experimentation is laborious and very labour intensive. There are several biofilm model that have been used in laboratory such as the closed growth model using solid media and membrane filter, continuous growth model using tubular model and others. In endodontic research, the most reliable and allows a more accurate assessment of antimicrobial efficacy thus far is the membrane filter based model $(9,10)$.

$\mathrm{NaOCl}$ is by far the most commonly used irrigant in endodontic therapy. It provides gross debridement, lubrication, destruction of microbes and dissolution of tissues. However, this irrigant lead to problems including toxicity, odour and discoloration of operatory items. Thus, an equally effective, but safer irrigant is desirable.

Ozone is a very powerful bactericide that can kill microorganisms effectively. It is an unstable gas, capable of oxidizing any biological entity. It was reported that ozone at low concentration, $0.1 \mathrm{ppm}$, is sufficient to inactivate bacterial cells including their spores (11). It is present naturally in air and can be easily produced by ozone generator. When introduced in water, ozone dissolves rapidly and dissociates rather quickly. The concentration of ozone in ozonated water can be measured using a dissolved ozone meter.

Although ozonated water is a powerful antimicrobial agent against bacteria, fungi, protozoa, and viruses, less attention has been paid to the antibacterial activity of ozonated water in bacterial biofilm (12) and hence in root canal infections. Therefore, it is the purpose of the present study to evaluate the antimicrobial effectiveness of ozonated water and $\mathrm{NaOCl}$ against E. faecalis biofilm. 


\section{MATERIALS \& METHODS}

\section{Bacterial strain}

E. faecalis strain was supplied as cultured in brain heart infusion broth plus $10 \%$ glycerol, BHIG (BHIG - Merck, Poole, UK) and were kept frozen $\left(-70^{\circ} \mathrm{C}\right)$. This procedure ensured mid-log-stationaryphase cells in all of the experiments (13). Throughout this study the pure culture were maintained and sub-cultured weekly and the stock were re-frozen in BHIG broth for future use.

\section{Test solutions}

In this study, $\mathrm{NaOCl}$ (Clorox Malaysia Sdn. Bhd.) and ozonated water were used as the test solutions. Concentration of $\mathrm{Clorox}^{\circledR}$ (Clorox Malaysia Sdn. Bhd.) was initially determined using standard thiosulphate titration method. Subsequently, the pure solution $(4.77 \%)$ was diluted to achieve the desired $\mathrm{NaOCl}$ concentration of $2.62 \%, 1.31 \%, 0.65 \%, 0.32 \%, 0.16 \%, 0.08 \%, 0.04 \%$ and $0.02 \%$. Fresh solution was prepared prior to each experimental testing.

Ozonated water was prepared using an ozone gas generator machine. The corona discharge ozone gas generator ORM AW600 (ORM beauty and health care SDN BHD) was used as the source of the ozone gas. The ozone gas produced from this ozonizer was introduced into 1 litre of de-ionized water for 20 minutes. The concentration of dissolved ozone in water was measured using an EcoZone $\mathrm{T}^{\mathrm{TM}}$ Model EZ10W Portable Dissolved Ozone Meter. The concentration of ozonated water used for this study was $0.1 \mathrm{ppm}$. Ozonated water was freshly prepared and was used within 20 minutes of preparation.

\section{Agar diffusion test - minimum inhibitory}

concentration (MIC) of test solutions

In the first part of this study, an agar diffusion test was carried out to determine the minimum concentration of test agents that produce zone of inhibition. Petri dishes containing Brain Heart Infusion (BHI) agar enriched with horse blood (BECTON DICKINSON, USA) were seeded with $E$. faecalis strain using sterile swabs that were brushed across the agar surfaces. $100 \mu \mathrm{L}$ of test solutions $(\mathrm{NaOCl}-4.77 \%, 2.62 \%, 1.31 \%, 0.65 \%, 0.32 \%$, $0.16 \%, 0.08 \%, 0.04 \%$ and $0.02 \%$; ozonated water at $0.1 \mathrm{ppm}$ ) were pipetted onto an individual paper disc $(13 \mathrm{~mm}$ in diameter) until all of the solution was absorbed. $\mathrm{NaOCl}$ at $4.77 \%$ acts as a positive control and distilled water as a negative control. The paper disks were then placed on top of the agar surface and incubated in aerobic condition at $37^{\circ} \mathrm{C}$ for 24 hours. All experiment was performed in triplicate $(n=3)$ for each of the test solutions. Following incubation, zone of inhibition were measured using a clear ruler. The minimum concentrations that produce zone of inhibition were recorded and act as baseline concentration for later part of the experiment.

\section{Minimum biofilm eradication concentration, MBEC}

The next part of the experiment involves determination of antimicrobial effect of test solutions against $E$. faecalis biofilm using a membrane filter model. E. faecalis was revived by inoculating on BHI agar (BECTON DICKINSON, USA) and incubated overnight in an aerobic incubator (Memmert, Germany) at $37^{\circ} \mathrm{C}$. The purity of the isolate was confirmed based on colony morphology and gram staining. A bacterial suspension was prepared by suspending a loop-full of $E$. faecalis colony from the culture into $10 \mathrm{~mL}$ of $0.85 \%$ sterile saline. The cell suspension was adjusted spectrophotometrically to match the turbidity of a McFarland $0.5 \quad \mathrm{BaSO}_{4}$ standard which was approximately $1.5 \times 10^{8}$ colony forming units $/ \mathrm{mL}$. An aliquot of $50 \mu \mathrm{L}$ of the suspension was seeded onto $13.0 \mathrm{~mm}$ diameter $(0.22 \mu \mathrm{m}$ pore diameter $)$ cellulose acetate membrane filters (Sartorius Malaysia Sdn. Bhd.) which were then placed on the surface of BHI agar enriched with horse blood. Six membranes were used for each plate. The plate was then incubated in an aerobic incubator at $37^{\circ} \mathrm{C}$ for 48 hours. Following incubation, non-adherent bacteria on the membrane filters was washed away by transferring the membrane filters aseptically with sterile tweezers from $\mathrm{BHI}$ agar plate into a universal bottle containing $10 \mathrm{~mL}$ of sterile phosphate buffered saline (PBS) solution. Each membrane filter was then transferred to a sterile universal bottle containing $5 \mathrm{~mL}$ of each concentration of test solution accordingly and kept for 1 minute. The antimicrobial activity of the test solution was then ceased by transferring the membrane into a universal bottle containing $5 \mathrm{~mL}$ of $1.93 \%$ sodium thiosulphate for neutralization of $0.5 \% \mathrm{NaOCl}$ and $3.86 \%$ sodium thiosulphate for neutralization of more than $1 \%$ $\mathrm{NaOCl}$ and $0.1 \mathrm{ppm}$ ozonated water accordingly. The membrane was then transferred to a $5 \mathrm{~mL}$ of BHI broth (BECTON DICKINSON, USA) and sonicated for 5 minutes in the ultrasonic bath (Segar Media Sdn. Bhd.). This helps in re-suspending the sessile bacteria from the membrane and produced a 'neat' bacterial suspension. Aliquot of $20 \mu \mathrm{L}$ of the bacterial suspension was then mixed into $180 \mu \mathrm{L}$ of BHI broth in microtiter plate (NUNC, Denmark). $50 \mu \mathrm{L}$ of the broth was then plated on BHI agar plate. Value of MBEC was then determined.

\section{CFU/biofilm at different exposure time}

In this part of the experiment, $5 \mathrm{~mL}$ of test solution $(2.62 \% \mathrm{NaOCl}$ and $0.1 \mathrm{ppm}$ ozonated water - the highest concentration at which bacteria can regrow) were prepared. Following incubation, nonadherent bacteria on the membrane filter was washed away by removing the membrane filter 
aseptically with sterile tweezers from BHI agar plate and transferred to a universal bottle containing $10 \mathrm{~mL}$ of sterile PBS solution. Each inoculated membrane filter was then transferred to each sterile universal bottle containing $5 \mathrm{~mL}$ of $2.62 \% \mathrm{NaOCl}(5$ bottles) or $0.1 \mathrm{ppm}$ ozonated water ( 5 bottles) accordingly.

At 0 min (i.e. no contact with the test solution), the individual inoculated membrane filters was removed aseptically with sterile tweezers from BHI agar plate, transferred to a sterile universal bottle containing $5 \mathrm{~mL}$ of PBS and subsequently to $5 \mathrm{~mL}$ of BHI broth and sonicated for 5 minutes to re-suspend the bacteria. This produced a "neat" bacterial suspension. Plating was carried out by aliquot 50 $\mu \mathrm{L}$ of the broth to BHI agar plate. The plate was then incubated for 24 hours in an aerobic incubator at $37^{\circ} \mathrm{C}$. The number of E. faecalis colonies on the agar surface was then manually calculated. The number of E. faecalis colony forming unit per biofilm (CFU/biofilm) was then enumerated. This was the negative control.

The biofilm was exposed to the test solution for $1,2,4,8,15,30$ and 60 minutes. Following this, the membrane filter from each test solution was transferred into a sterile universal bottle containing $5 \mathrm{~mL}$ of $3.86 \%$ sodium thiosulphate to stop any further action of the test solution on the biofilm. Subsequently, the membrane filter was transferred into a sterile universal bottle containing $5 \mathrm{~mL}$ of BHI broth. All universal bottles were sonicated for 5 minutes to re-suspend the bacteria from the biofilm. 10 -fold serial dilution was performed in sterile microtitre plate by mixing $20 \mu \mathrm{L}$ of the bacterial suspension into $180 \mu \mathrm{L}$ of $\mathrm{BHI}$ broth. $50 \mu \mathrm{L}$ from each dilution was then plated on BHI agar plate. The plates were then incubated for 24 hours in an aerobic incubator at $37^{\circ} \mathrm{C}$. The number of $E$. faecalis CFU/biofilm was then manually calculated.

The data collected was compared within and between groups whereby One-way ANOVA was used. Variances were compared using Levene's statistics. Since the homogeneity of variances assumption was not meet, the non-parametric Kruskal-Wallis test was performed. The level of significance was set at $5 \%(p=0.05)$.

\section{RESULTS}

\section{MIC of test solutions}

Table 1 represents the mean diameter of zone of inhibition $(\mathrm{mm})$ for various concentration of $\mathrm{NaOCl}$ and $0.1 \mathrm{ppm}$ of ozonated water. Distilled water (DW) was used as control. At concentration of $4.77 \%$, $\mathrm{NaOCl}$ was capable in producing a mean diameter of $32 \mathrm{~mm}$ of zone of inhibition. At $0.02 \%$, however, $\mathrm{NaOCl}$ did not produce any zone of inhibition. For ozonated water, the mean diameter of zone of inhibition produced was $14.0 \mathrm{~mm}$.

\section{Determination of MBEC}

Table 2 represents the mean value of CFU/ biofilm using range of concentration of $\mathrm{NaOCl}$ and $0.1 \mathrm{ppm}$ of ozonated water against $E$. faecalis biofilm. DW was used as control. The result showed that $\boldsymbol{E}$. faecalis biofilm can be totally eradicated $(100 \%$ kill) by $4.77 \%$ of $\mathrm{NaOCl}$. However at concentration of $1.31 \%$ and below, confluence growth were detected. Similarly, when tested with $0.1 \mathrm{ppm}$ ozonated water, confluence growth was observed.

\section{CFU/biofilm at different exposure time}

Table 3 represents mean CFU/biofilm with $2.62 \%, 1.31 \% \mathrm{NaOCl}, 0.1 \mathrm{ppm}$ ozonated water and combination of $1.31 \% \mathrm{NaOCl}$ and $0.1 \mathrm{ppm}$ ozonated water at $1,2,4,8,15,30$ and 60 minutes of exposure time. $2.62 \% \mathrm{NaOCl}$ can only achieved $100 \%$ kill after 15 minutes of exposure time. However, with $1.31 \%$ $\mathrm{NaOCl}$, reducing number (by $2 \log _{10}$ ) of $E$. faecalis colony can only be seen after 30 minutes of exposure time and $100 \%$ kill was only achieved after 60 minutes of exposure time. In the case of $0.1 \mathrm{ppm}$ ozonated water, some reduction in CFU count was observed after $30 \mathrm{~min}$ exposure time. 100\% kill was

Table 1. Agar diffusion test - Mean diameter of zone of inhibition $(\mathrm{mm})$ of $\mathrm{NaOCl}$ and ozonated water $(n=3)$

\begin{tabular}{lcc}
\hline Concentration & & $\begin{array}{c}\text { Mean diameter of } \\
\text { zone of inhibition } \\
(\mathrm{mm})\end{array}$ \\
\hline $\mathrm{NaOCl}(\%)$ & 4.77 & $\mathbf{3 2 . 0}$ \\
(Available chlorine) & 2.62 & 30.0 \\
& 1.31 & 23.1 \\
& 0.65 & 18.5 \\
& 0.32 & 16.0 \\
& 0.16 & 16.3 \\
Ozonated water (ppm) & 0.08 & 15.0 \\
DW (C) & 0.04 & 14.0 \\
& $\mathbf{0 . 0 2}$ & $\mathrm{NI}$ \\
& $\mathbf{0 . 1 0}$ & $\mathbf{1 4 . 0}$ \\
\hline
\end{tabular}

$\mathrm{DW}(\mathrm{C})$ - Distilled water (control), $\mathrm{NI}$ - No inhibition

Table 2. MBEC of $\mathrm{NaOCl} \&$ ozonated water $(n=3)$

\begin{tabular}{lcc}
\hline \multicolumn{2}{c}{ Concentration } & Mean CFU/biofilm \\
\hline $\mathrm{NaOCl}(\%)$ & 4.77 & 0 \\
(available chlorine) & 2.62 & 15.3 \\
& 1.31 & $\mathrm{CG}$ \\
& 0.65 & $\mathrm{CG}$ \\
Ozonated water (ppm) & 0.10 & $\mathrm{CG}$ \\
DW (C) & & $\mathrm{CG}$ \\
\hline
\end{tabular}

$\mathrm{DW}(\mathrm{C})$ - Distilled water, $\mathrm{CG}$-Confluence growth 
Table 3. Mean values and standard deviation (SD) of CFU counts (CFU/biofilm) following exposure to different test solutions at different exposure time $(n=4)$

\begin{tabular}{|c|c|c|c|c|c|c|c|}
\hline \multirow{2}{*}{ Test agent } & \multicolumn{7}{|c|}{ Exposure time (min) } \\
\hline & 1 & 2 & 4 & 8 & 15 & 30 & 60 \\
\hline $\begin{array}{l}2.62 \% \\
\mathrm{NaOCI}(\mathrm{SD})\end{array}$ & $\begin{array}{l}1.3 \times 10^{4} \\
\left(0.5 \times 10^{4}\right)\end{array}$ & $\begin{array}{l}4.1 \times 10^{3} \\
\left(1.8 \times 10^{3}\right)\end{array}$ & $\begin{array}{l}1.0 \times 10^{4} \\
\left(0.3 \times 10^{4}\right)\end{array}$ & $\begin{array}{l}8.0 \times 10^{3} \\
\left(1.5 \times 10^{3}\right)\end{array}$ & 0 & 0 & 0 \\
\hline $\begin{array}{l}1.31 \% \\
\mathrm{NaOCI}(\mathrm{SD})\end{array}$ & $\begin{array}{l}\left(6.0 \times 10^{5}\right)^{*} \\
(-)\end{array}$ & $\begin{array}{l}\left(6.0 \times 10^{5}\right)^{*} \\
(-)\end{array}$ & $\begin{array}{l}\left(6.0 \times 10^{5}\right)^{*} \\
(-)\end{array}$ & $\begin{array}{l}\left(6.0 \times 10^{5}\right)^{*} \\
(-)\end{array}$ & $\begin{array}{l}\left(6.0 \times 10^{5}\right)^{*} \\
(-)\end{array}$ & $\begin{array}{l}2.4 \times 10^{3} \\
\left(0.5 \times 10^{3}\right)\end{array}$ & 0 \\
\hline $\begin{array}{l}0.1 \mathrm{ppm} \\
\text { OW (SD) }\end{array}$ & $\begin{array}{l}\left(6.0 \times 10^{5}\right)^{*} \\
(-)\end{array}$ & $\begin{array}{l}\left(6.0 \times 10^{5}\right)^{*} \\
(-)\end{array}$ & $\begin{array}{l}\left(6.0 \times 10^{5}\right)^{*} \\
(-)\end{array}$ & $\begin{array}{l}\left(6.0 \times 10^{5}\right)^{*} \\
(-)\end{array}$ & $\begin{array}{l}\left(6.0 \times 10^{5}\right)^{*} \\
(-)\end{array}$ & $\begin{array}{l}1.7 \times 10^{5} \\
\left(0.2 \times 10^{5}\right)\end{array}$ & $\begin{array}{l}1.4 \times 10^{5} \\
\left(0.4 \times 10^{5}\right)\end{array}$ \\
\hline $\begin{array}{l}1.31 \% \mathrm{NaOCl} \\
+0.1 \mathrm{ppm} \\
\mathrm{OW}(\mathrm{SD})\end{array}$ & $\begin{array}{l}\left(6.0 \times 10^{5}\right)^{*} \\
(-)\end{array}$ & $\begin{array}{l}\left(6.0 \times 10^{5}\right)^{*} \\
(-)\end{array}$ & $\begin{array}{l}\left(6.0 \times 10^{5}\right)^{*} \\
(-)\end{array}$ & $\begin{array}{l}\left(6.0 \times 10^{5}\right)^{*} \\
(-)\end{array}$ & $\begin{array}{l}5.9 \times 10^{3} \\
\left(1.5 \times 10^{3}\right)\end{array}$ & 0 & 0 \\
\hline $\mathrm{DW}(\mathrm{SD})$ & $\begin{array}{l}\left(6.0 \times 10^{5}\right)^{*} \\
(-)\end{array}$ & $\begin{array}{l}\left(6.0 \times 10^{5}\right)^{*} \\
(-)\end{array}$ & $\begin{array}{l}\left(6.0 \times 10^{5}\right)^{*} \\
(-)\end{array}$ & $\begin{array}{l}\left(6.0 \times 10^{5}\right)^{*} \\
(-)\end{array}$ & $\begin{array}{l}\left(6.0 \times 10^{5}\right)^{*} \\
(-)\end{array}$ & $\begin{array}{l}\left(6.0 \times 10^{5}\right)^{*} \\
(-)\end{array}$ & $\begin{array}{l}\left(6.0 \times 10^{5}\right)^{*} \\
(-)\end{array}$ \\
\hline
\end{tabular}

DW - Distilled water, OW - Ozonated water, ()$^{\star}$ means Confluence growth $(C G)=6.0 \times 10^{5}$

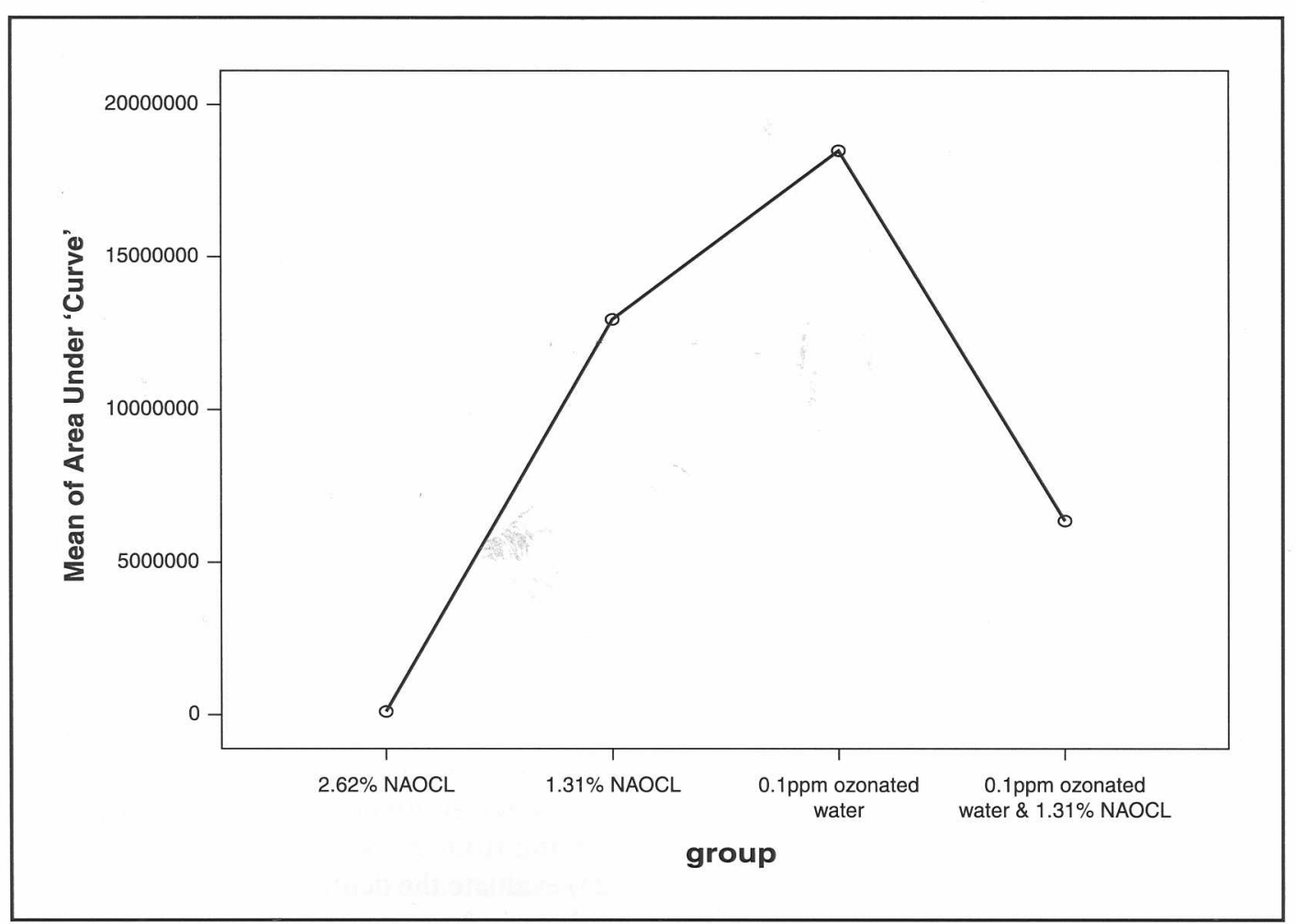

Figure 1: Mean plot of Area under 'curve' for various test agents for a period of time tested (n=4).

however not achievable even after 60 minutes of exposure time.

\section{Statistical analysis}

Figure 1 showed mean plot for different group of test agents. Since the time tested is not consistent, the mean of Area under 'curve' was measured and represent the mean $\mathrm{CFU}$ for the period of time tested i.e. 60 minutes. $0.1 \mathrm{ppm}$ ozonated water showed the highest mean CFU after 60 minutes exposure time

Table 4 showed result from non parametric test in comparison between groups of test agent. Since the p-value is less than 0.05 , at least one pair is different. The result was further tested to see multiple comparisons using Dunnett T3, as in Table 5. This 
Table 4. Results from nonparametric test

\begin{tabular}{lccc}
\hline Group (test agents) & $\mathrm{n}$ & Mean Rank & $\mathrm{p}$-value \\
\hline $2.62 \% \mathrm{NaOCl}$ & 4 & 2.50 & \\
$1.31 \% \mathrm{NaOCl}$ & 4 & 10.50 & $\mathbf{0 . 0 0 3}$ \\
$0.1 \mathrm{ppm}$ ozonated water & 4 & 14.50 & \\
$\begin{array}{l}\text { 0.1ppm ozonated water \& } \\
1.31 \% \mathrm{NaOCl}\end{array}$ & 4 & 6.50 & \\
Total & 16 & & \\
\hline
\end{tabular}

Table 5. Multiple comparisons using Dunnett T3

\begin{tabular}{|c|c|c|}
\hline Group & Group & Sig. \\
\hline $2.62 \%$ & $1.31 \% \mathrm{NaOCl}$ & .000 \\
\hline \multirow[t]{2}{*}{$\mathrm{NaOCl}$} & $0.1 \mathrm{ppm}$ ozonated water & .000 \\
\hline & $0.1 \mathrm{ppm}$ ozonated water $\& 1.31 \% \mathrm{NaOCl}$ & .000 \\
\hline $1.31 \%$ & $0.1 \mathrm{ppm}$ ozonated water & .006 \\
\hline $\mathrm{NaOCl}$ & $0.1 \mathrm{ppm}$ ozonated water \& $1.31 \% \mathrm{NaOCl}$ & .000 \\
\hline $\begin{array}{l}0.1 \mathrm{ppm} \\
\text { ozonated } \\
\text { water }\end{array}$ & $0.1 \mathrm{ppm}$ ozonated water \& $1.31 \% \mathrm{NaOCl}$ & .001 \\
\hline
\end{tabular}

Dependent variable: Area under curve

table revealed that the p-values for all pair-wise comparisons are less than 0.05 therefore all groups are significantly different from each other in term of their antimicrobial effectiveness. The most significant different was $2.62 \% \mathrm{NaOCl}$ in comparison to other test groups.

\section{DISCUSSION}

E. faecalis was chosen as it is considered as one of the most resistant species encountered in the root canal system $(2,14)$. In addition, some studies have shown that the bacteria are capable to survive as a mono-infection in roots canals $(15,16)$ and can invade dentinal tubules (17).

In the present study, $\mathrm{NaOCl}$ was used as one of the test agents due to its well known antimicrobial action. However, no general agreement exists regarding its optimal concentration, which range from $0.5 \%$ to $5.25 \%$.

Ozone is a powerful oxidizing agent (11) and was stated to have an antimicrobial property (18). When it is dissolved in water, ozonated water becomes highly unstable and rapidly decomposed through a complex series of chain reactions (19). This resulted in the production of hydroxyl $\left(\mathrm{OH}^{-}\right)$radicals which were amongst the most reactive oxidizing agent.

Agar diffusion test is the widely accepted method in evaluating antibacterial activities of dental materials and medicaments (20). This method allows direct comparison of the tested agent against the test microorganisms. Although determination of MIC is the standard procedure in evaluating antimicrobial effect of test agent, however, it did not take into account that target microorganisms may exist in the form of a biofilm. Therefore, in this study MIC of the test agents was first determined acting as a baseline concentration prior to MBEC. The MBEC was then performed to obtain the initial test concentration, thus allowing consideration of existence of microorganisms in the form of biofilm.

In this study, membrane filter model was used to form the biofilm. This technique offers a simple means of determining the susceptibility of oral bacterial biofilm to antimicrobial agents. In addition, it is reproducible and easy to be used. Nevertheless, it is perhaps more relevant to test effectiveness of test solution in a tooth model. However, considering the anatomical variety of the root canal system and individual growth responses within each tooth during the incubation periods, these factors might lead to biased in data and wide confidence intervals. Thus, it will require a larger sample size in order to increase confidence in the estimates. Moreover, collection, selection and preparation of tooth sample would be quite laborious.

In this study the inoculated membrane filter was incubated for $48 \mathrm{hr}$. Gulabivala et al. (21) in their pilot study had established that the 48-hr time-frame was sufficient to develop single species biofilm.

The volume of all test solutions were standardized to $5 \mathrm{~mL}$ each and no attempt was made to test on different volume applied to antimicrobial effect since clinically it is the replenish activity that plays an important role in eliminating the microorganism and debris rather than extended volume.

Previous studies have shown that $\mathrm{NaOCl}$ was a very effective agent in disinfecting the root canal. Its optimal concentration is still debatable. Siqueira et al. (22) reported that from clinical and laboratory studies, there is no significant difference in antibacterial effect between $\mathrm{NaOCl}$ concentration ranging from $0.5 \%$ to $5.0 \%$. However, Berber et al. (23) evaluate the dentinal tubules following irrigation with various concentration of $\mathrm{NaOCl}$. In this study, $0.50 \%, 2.50 \%$ and $5.25 \% \mathrm{NaOCl}$ were tested associated with hand and rotary instrumentation techniques against $E$. faecalis within root canals and dentinal tubules. $5.25 \%$ was shown to be the most effective irrigant solution tested when dentinal tubules were analysed, followed by $2.50 \%$ regardless of the canal preparation technique used. However, no differences among concentrations in cleaning the canals were found. In the present study, $4.77 \%$ $\mathrm{NaOCl}$ was shown to be an effective antimicrobial action after $1 \mathrm{~min}$ exposure whereas $2.62 \% \mathrm{NaOCl}$ 
require $15 \mathrm{~min}$ to be fully effective. In addition, with reduced concentration, $1.31 \%$, an additional time was needed to produce such similar effect. This result is in line with Radcliffe et al. (24) in which their finding indicated a significant interaction between tested time and concentration of $\mathrm{NaOCl}$. They found that when higher concentration was employed, less time was required to attain zero viable counts of E. faecalis colony.

In contrast with the present study, Nagayoshi et al. (12) found that killing ability of ozonated water and $2.5 \%$ of sodium hypochlorite was almost comparable when the specimen was irrigated with sonication. However, in this study, microorganisms in dental plaque such as Streptococcus salivarius and Streptococcus sanguis were used. These microorganisms were proven not as resistant as E. faecalis. Furthermore, they did not existed as biofilm form during testing, as sonication resulted in bacterial in biofilm to be converted into planktonic form.

Study by Hems et al. (25) however found that $\mathrm{NaOCl}$ was superior to ozonated water in killing $E$. faecalis in broth culture and in biofilm. In this study, sparging ozone with and without stirring was used to detach the bacteria from biofilm model. In a separate test, biofilm was also exposed to gaseous ozone. It was found that gaseous ozone had no significant effect on E. faecalis viability in biofilm. Biofilm incubated for 240 seconds with ozonated water showed no significant reduction in cell viability attributable to ozone alone compared to $\mathrm{NaOCl}$ (control) over same condition. They concluded that ozone had an antibacterial effect on planktonic $E$. faecalis cells and those suspended in fluid, but little effect when embedded in biofilm. The conclusion of this study was similar with the finding of the present study although different method in ozone application was employed.

Abdullah et al., (10) compared susceptibility of different $E$. faecalis presentation i.e. planktonic, biofilm and pellet form to various root canal irrigants and medications. One of their findings was irrigant and medication which have tissue dissolving capabilities such as $\mathrm{NaOCl}$ and $\mathrm{Ca}(\mathrm{OH})_{2}$ respectively, showed effective antimicrobial activity regardless of the bacterial presentation compared to those that did not possess the tissue dissolving property such as chlorhexidine and iodine. These former medications may be less inhibited in its antimicrobial action by the extracellular polysaccharide matrix in biofilm. In agreement with this study, Hems et al., (25) and the present study found that ozone had no effect on E. faecalis cells in the biofilm. The resistance of the bacterial cells in the biofilm must be attributed to the depletion of ozone as it diffuses into the biofilm by virtue of its organic composition. The biofilm extracellular polysaccharide matrix, therefore, probably protects against ozone.
In this study it was found that combination of $1.31 \% \mathrm{NaOCl} \& 0.1 \mathrm{ppm}$ of ozonated water was shown to reduce CFU count than $1.31 \% \mathrm{NaOCl}$ alone. The oxidation effect of ozone might interfere with chloramination of $\mathrm{NaOCl}$. Abdullah et al., (10) stated that tissue dissolving property of $\mathrm{NaOCl}$ at e" $1 \%$ may enhance the antibacterial effects of other agents. Likewise in the present study, $1.31 \% \mathrm{NaOCl}$ might allow passage of oxidation of ozonated water, thus increase their antibacterial effect compared to $1.31 \% \mathrm{NaOCl}$ or ozonated water alone.

The stock solution of $\mathrm{NaOCl}\left(\mathrm{Clorox}^{\circledR}\right)$ was $0.48 \%$ less concentrated $(4.77 \%)$ than the expected concentration $(5.25 \%)$ when tested upon initial receipt. Thus $\mathrm{NaOCl}$ should ideally be assayed/ titrate before dilution prior to testing if accurate concentrations are required to preserve its available chlorine. Nevertheless, pilot studies on effect of storage on concentration of available chlorine in $\mathrm{NaOCl}$ revealed that there was no significant difference in available chlorine at baseline after storage at room temperature for 6 months.

\section{CONCLUSION}

In conclusion, the antimicrobial effect of $\mathrm{NaOCl}$ reduced with concentration below $1.31 \%$, however increased with an increased time but only fully effective at $15 \mathrm{~min}$ for $2.62 \%$ and $60 \mathrm{~min}$ for $1.31 \%$. $0.1 \mathrm{ppm}$ of ozonated water can reduce the viable bacteria colony number but cannot totally eliminate E. faecalis biofilm even after 60 minutes of exposure time. $0.1 \mathrm{ppm}$ of ozonated water was proven not comparable with $\mathrm{NaOCl}$ in the antimicrobial effect against $E$. faecalis biofilm.

\section{REFERENCES}

1. Kakehashi S, Stanley HR, Fitzgerald RJ, Bethesda. The effects of surgical exposures of dental pulps in germ-free and conventional laboratory rats. Oral Surgery, Oral Medicine, Oral Pathology 1965; 20: 340-349.

2. Molander A, Reit C, Dahlén G, Kvist T. Microbiological status of root filled teeth with apical periodontitis. Int Endo J 1998; 31: 1-7.

3. Chvez de Paz LE, Dahl-n G, Molander A, Möller A, Bergenholtz G. Bacteria recovered from teeth with apical periodontitis after antimicrobial endodontic treatment. Int Endo J 2003; 36: 500-508.

4. Haapasalo M, Ørstavik D. In vitro infection and disinfection of dentinal tubules. J of Dent Res 1987; 66: 1375-1379. 
5. Morrison D, Woodford N, Cooleson B. Enterococci as emerging pathogens of humans. J of Appl Microbiology 1997; 83: 89s-99s.

6. Costerton JW, Cheng KJ, Geesey GG, Ladd TI, Nickel JC, Desgupta M, Martie TJ. Bacterial biofilm in nature and disease. Annals Rev microbiology 1987; 41: 435-464.

7. Shih M, Marshal FJ, Rosen SR. The bactericidal efficiency of sodium hypochlorite as an endodontic irrigant. Oral Surgery, Oral Medicine, Oral Pathology 1970; 29: 613-9.

8. Foley DB, Weine FS, Hagen JC, Deobarrio JJ. Effectiveness of selected irrigants in the elimination of Bacteroides melaninogenicus from the root canal system: An in vitro study. J of Endo 1983; 9: 236-241.

9. Spratt DA, Pratten J, Wilson M, Gulabivala K. An in vitro evaluation of the antimicrobial efficacy of irrigants on biofilms of root canal isolates. Int Endo J 2001; 34: 300-307.

10. Abdullah M, Ng Y-L, Gulabivala K, Moles DR, Spratt DA. Susceptibility of two Enterococcus faecalis phenotypes to root canal medications. J of Endo 2005; 31: 30-36.

11. Broadwater WT, Hoehn RC, King PH. Sensitivity of three selected bacterial species to ozone. Appl Microbiology 1973; 26: 391-393.

12. Nagayoshi M, Kitamura C, Fukuizumi T, Nishihara T, Terashita M. Antimicrobial effect of ozonated water on bacteria invading dentinal tubules. J of Endo 2004; 30: 778-781.

13. Heling I, Rotstein I, Dinur T, Szwec-Levine Y, Steinberg D. Bactericidal and cytotoxic effects of sodium hypochlorite and sodium dichloroisocyanurate solutions in vitro. $J$ of Endo 2001; 27: 278-280.

14. Sundqvist G, Figdor D, Persson S, Sjögren U. Microbiologic analysis of teeth with failed endodontic treatment. Oral Surgery, Oral Medicine, Oral Pathology 1998; 85: 86-93.

15. Moller AJR, Fabricius L, Dahlén G, Othman $\mathrm{AE}$, Heyden $\mathrm{G}$. Influence on periapical tissues of indigenous oral bacteria and necrotic pulp tissue in monkeys. Scand J of Dent Res 1981; 89: 475-84.
16. Fabricius L, Dahlén G, Öhman AE, Möller AJR. Predominant indigenous oral bacteria isolated from infected root canals after varied times of closure. Scand J of Dent Res 1982; 90: 134-144.

17. Ørstavik D, Haapasalo M. Disinfection by endodontic irrigants and dressings of experimentally infected dentinal tubules. Endod Dent Traumatol 1990; 6:142-149.

18. Baysan A, Whiley RA, Lynch E. Antimicrobial effect of a novel ozone-generating device on micro-organisms associated with primary root carious lesions in vitro. Caries Res 2000; 34: 498501.

19. Hoigné J, Bader H. The role of hydroxyl radical reactions in ozonation processes in aqueous solution. Water Res 1976; 10: 377-86.

20. Siqueira JF, De Uzeda M, Fonseca MEF. A scanning electron microscopic evaluation of in vitro dentinal tubules penetration by selected anaerobic bacteria. J of Endo 1996; 22: 308-310.

21. Gulabivala K, Stock CJ, Lewsey JD, Ghori S, Ng. Y-L, Spratt DA. Effectiveness of electrochemically activated water as an irrigant in an infected tooth model. Int Endo J 2004; 37: 624631.

22. Siqueira JF, Rôças IN, Favieri A, Lima KC. Chemomechanical reduction of the bacterial population in the root canal after instrumentation and irrigation with 1\%, $2.5 \%$ and $5.25 \%$ sodium hypochloride. $\mathrm{J}$ of Endo 2000; 26: 331-334.

23. Berber VB, Gomez BPFA, Sena NT, Vianna ME, Ferraz CCR, Zaia AA, Souza-Filho FJ. Efficacy of various concentrations of $\mathrm{NaOCl}$ and instrumentation techniques in reducing Enterococcus faecalis within root canals and dentinal tubules. Int Endo J 2006; 39: 10-17.

24. Racdliffe CE, Potouridou L, Qureshi R, Habahbeh N, Qualtrough A, Worthington H, Drucker DB. Antimicrobial activity of varying concentrations of sodium hypochlorite on the endodontic microorganisms Actinomyces israelii, A. naeslundii, Candida albicans and Enterococcus faecalis. Int Endo J 2004; 37:438-446.

25. Hems RS, Gulabivala K, Ng Y-L, Ready D, Spratt DA. An in vitro evaluation of the ability of ozone to kill a strain of Enterococcus faecalis. Int Endo J 2005; 38: 22- 29. 